\title{
MEKANIKA GAYA APUNG PADA OLAHRAGA RENANG
}

\author{
Hermi Sunandarti \\ Universitas Bengkulu \\ sunandarti18@gmail.com \\ Sugiyanto \\ Universitas Bengkulu \\ Bayu Insanistyo \\ Universitas Bengkulu
}

\begin{abstract}
Abstrak
Penelitian ini bertujuan untuk mengertahui bagaimana gaya apung pada olahraga renang. Jenis penelitian ini adalah penelitian deskriptif. Sampel yang digunakan merupakan mahasiswa penjaskesrek semester 2 Universitas Bengkulu yang berjumlah 77 orang yang terdiri dari 62 orang putra dan 15 orang putri. Teknik pengumpulan data yang digunakan mengunakan teknik pengamatan (observasi), tes dan pengukuran. Instrument yang digunakan adalah dengan menggunakan rating scale, check list dan dokumentasi serta tes dan pengukuran antropometri. Hasil penelitian dari gaya apung mahasiswa penjaskesrek yang berjumlah 77 orang maka diperoleh hasil, bahwa mahasiswa dengan keadaan atau posisi mengapung sebayak 39 orang atau sama dengan 50,64\%, mahasiswa dengan keadaan atau posisi melayang sebanyak 19 orang atau sama dengan 24,67\% dan mahasiswa dengan keadaan atau posisi tenggelam sebanyak 19 orang atau 24,67\%. Kesimpulan dari hasil pengamatan, tes dan pengukuran dapat dilihat bahwa setiap mahasiswa mempunyai gaya apung yang berbeda pada saat berada di dalam air.
\end{abstract}

Kata Kunci : Gaya Apung, Mahasiswa Penjaskesrek Universitas Bengkulu

\begin{abstract}
This study aims to understand how the buoyancy style in sports pool. The type of this research is descriptive research. The sample used is the students of semester 2 Bengkulu University, amounting to 77 people consisting of 62 male and 15 females. Technique of collecting data used observation technique (observation), test and measurement. The instrument used is by rating scale, check list and documentation as well as anthropometric tests and measurements. The result of research from the floating style of student penjaskesrek which amounted to 77 people then obtained the result, that students with the condition or position of float as much 39 people or equal to 50,64\%, student with state or position float as much 19 people or equal to $24,67 \%$ and Students with the condition or the drowning position as many as 19
\end{abstract}


people or $24.67 \%$. Conclusions from observations, tests and measurements can be seen that each student has a different buoyancy style when in the water.

Keywords: buoyancy, student penjaskesrek University of Bengkulu.

\section{PENDAHULUAN}

Berenang merupakan olahraga yang dilakukan di dalam air, berbeda dengan olahraga lainnya yang dilakukan di darat. Gerakan renang olahraga renang muncul sebagai tuntutan manusia dalam memenuhi kebutuhan hidupnya dan mempertahankan diri. Pesatnya kemajuan ilmu pengetahuan dan teknologi membuat kemajuan dan perkembangan olahraga renang semakin pesat. Salah satunya pada saat kita melakukan gerakan pada olahraga renang yang baik harus bisa dijelaskan berdasarkan ilmu mekanika. Tiga hal yang harus dikuasai sebelum mempelajari gaya dalam olahrag renang diantaranya bernafas, mengapung dan meluncur. Mengapung merupakan salah satu mekanisme yang harus diperhatikan dalam olahraga renang. Gaya apung berbanding terbalik dengan dengan gaya berat. Gaya apung disebabkan benda atau tubuh seseorang yang berada dalam fluida dan gaya dinamika dikarenakan adanya gerakan relatif dalam fluida tersebut. Gaya dinamika biasanya terdiri dari dua komponen: gaya tarik (drag force) dan gaya angkat (lift force). Menurut McGinnis (2010:244) "Gaya angkat adalah gaya dari fluida yang dinamis untuk membuat objek bergerak secara tegak lurus pada gerak relatif objek yang berhubungan dengan fluida". Gaya angkat mengarahkan gerakan naik dan turun secara tegak lurus.
Kemampuan mengapung yang berbeda yang menjadikan setiap mahasiswa mempunyai kemampuan berenang yang berbeda. Karena olahraga renang merupakan olahraga yang dilakukan di dalam air, berbeda dengan olahraga lainnya yang dilakukan di darat. banyaknya mahasiswa yang belum memahami tentang teknik dasar dan mekanika dalam mengapung yang membuat mahasiswa mengalami kesulitan untuk melakukan gerakan mengapung. Ada banyak kesulitan yang dialami mahasiswa pada saat mengapung di atas air yang membuat mereka sulit untuk mempelajari berbagai macam gaya dalam olahraga renang. rumusan masalah dalam penelitian ini adalah sebagai berikut"Bagaimana status gaya apung pada mahasiswa penjaskesrek semester 2 Universitas Bengkulu?. Tujuan penelitian ini adalah Untuk mengetahui status gaya apung pada mahasiswa penjaskesrek semedter 2 Universitas Bengkulu. Dengan adanya penelitian ini diharapkan dapat bermanfaat baik secara terotis maupun praktis.

Olahraga renang terdapat suatu prinsip ekonomis mengeluarkan modal sekecil mungkin dan memperoleh untung sebesar mungkin. Demikian pula dengan renang memiliki prinsip yang sama mengeluarkan tenaga sekecil mungkin, dan mendapatkan daya laju yang seoptimal mungkin. Pada prinsipnya sikap mengapung dilakukan sebagai wujud dari perpindahan 
pusat titik berat (Center Of Gravity). hukum Archimedes menjelaskan "bila sebuah benda berada dalam air, ia akan mendapatkan tekanan keatas yang besarnya sama dengan berat air yang dipindahkan oleh benda tersebut." Hidrostatis adalah suatu studi tentang gaya apung yaitu kemampuan tubuh pada sikap terapung di air bila perenang memiliki karakteristik dan kemampuan gaya apung positif, maka akan memiliki gaya apung yang baik di air. Sebaliknya apabila memiliki karakteristik dan kemampuan negatif, maka akan memiliki karakteristik dan kemampuan negatif, apabila memiliki karakteristik dan kemampuan negatif, maka akan memiliki gaya apung yang rendah. Gaya apung merupakan kemampuan suatu benda untuk mengapung dalam air. Hubungan berat benda dengan berat air yang dipindahkan adalah yang menentukan apakah benda dapat mengapung atau tidak meskipun ukuran dan juga bentuk dari benda akan memiliki efek. Munurut MCGinnis (2010:244)" gaya apung disebabkan berada dalam fluida dan gaya dinamika dikarenakan adanya gerakan relatif dalam fluida tersebut. Ada atas 3 kemungkinan yang terjadi pada saat di dalam air (kolam renang) yaitu: 1 . Mengapung, jika berat jenis benda < 1 atau $(G A>G B), 2$. Melayang, jika berat jenis benda $=1$ atau $(\mathrm{GA}=\mathrm{GB})$, 3. Tenggelam, jika $>1$ atau $(G A<G B)$. Keterangan 1 merupakan berat jenis air.

\section{METODE}

Jenis penelitian yang digunakan dalam penelitian ini adalah jenis penelitian deskriptif. Sampel diambil dengan tehnik total sampling, 77 orang. Jadi jumlah sampel adalah 77 orang. Instrument untuk analisis status gaya apung adalah dengan pengamatan (observasi), tes dan pengukuran. Pengumpulan data dengan pengamatan (observasi) dengan instrument yang digunakan rating scale, check list, dan dokumentasi, dan tes antropometri. Teknik analisis data yang digunakan untuk menguji data yang telah diperoleh adalah dengan statistik deskriptif (tabulasi frekuansi) dengan cara mendeskripsikan hasil pengamatan yang diperoleh dari pengukuran (tes) terhadap status gaya apung yang diperoleh.

\section{HASIL DAN PEMBAHASAN}

Data yang diperoleh melalui penjumlahan dari hasil pengamatan (observasi) terhadap gaya apung mahasiswa penjaskesrek semester 2 Universitas Bengkulu. yang berjumlah 77 orang dengan menggunakan rating scale dan check list maka di peroleh hasil, bahwa mahasiswa dengan keadaan atau posisi Mengapung sebanyak 39 orang atau sama dengan $50,64 \%$, mahasiswa dengan keadaan atau posisi Melayang sebanyak 19 orang atau sama dengan 24,67\%, dan mahasiswa dengan keadaan atau posisi tenggelam sebanyak 19 orang atau sama dengan $24,67 \%$. Hasil pengamatan dapat dilihat dari tabel dibawah ini.

Tabel 1. Pengelompokkan status gaya apung.

\begin{tabular}{|c|c|c|c|}
\hline No & $\begin{array}{c}\text { Kategori } \\
\text { gaya apung }\end{array}$ & $\begin{array}{l}\text { Frekuensi } \\
\text { Absolut }\end{array}$ & $\begin{array}{c}\text { Frekuansi } \\
\text { Relative } \\
\text { (\%) }\end{array}$ \\
\hline 1 & Mengapung & 39 & 50,64 \\
\hline 2 & Melayang & 19 & 24,67 \\
\hline 3 & tenggelam & 19 & 24,67 \\
\hline & Jumlah & 77 & 100 \\
\hline
\end{tabular}


Perolehan tes antropometri yaitu IMT dan Presentase lemak sebagai tes pendukung dari perolehan data gaya apung yang di peroleh dari hasil pengamatan (observasi) yang dilakukan terhadap gaya apung. Hasil tes dan pengukuran antropometri dapat dilihat dari tabel di bawah ini.

Tabel 2.Pengelompokkan kategori IMT (Indeks Massa Tubuh)

\begin{tabular}{|clcc|} 
No & $\begin{array}{c}\text { Kategori } \\
\text { IMT }\end{array}$ & $\begin{array}{c}\text { Frekueansi } \\
\text { Absolut }\end{array}$ & $\begin{array}{c}\text { Frekuensi } \\
\text { Relative } \\
(\%)\end{array}$ \\
\hline 1 & $\begin{array}{l}\text { Sangat } \\
\text { kurus }\end{array}$ & 0 & 0,00 \\
\hline 2 & Kurus & 8 & 10,3 \\
\hline 3 & Ideal & 64 & 83,11 \\
\hline 4 & Gemuk & 3 & 3,89 \\
\hline 5 & $\begin{array}{l}\text { Sangat } \\
\text { gemuk }\end{array}$ & 2 & 2,95 \\
\hline & 77 & 100 \\
\hline
\end{tabular}

Tabel 3.Pengelompokkan presentase lemak

\begin{tabular}{|clcc|}
\hline No & $\begin{array}{c}\text { Kategori } \\
\text { IMT }\end{array}$ & $\begin{array}{c}\text { Frekuean } \\
\text { si Absolut }\end{array}$ & $\begin{array}{c}\text { Frekuensi } \\
\text { Relative } \\
(\%)\end{array}$ \\
\hline 1 & Kurang & 19 & 24,67 \\
\hline 2 & Baik & 18 & 23,37 \\
\hline 3 & Cukup & 18 & 23,37 \\
\hline 4 & Lebih & 19 & 24,67 \\
\hline 5 & Gemuk & 3 & 3,89 \\
\hline & Jumlah & 77 & 100 \\
\hline
\end{tabular}

Keadaan atau kondisi tubuh apa adanya, tanpa rekayasa atau usaha dari seseorang untuk membuat keadaan tubuh mereka sesuai yang di inginkan, karena gaya apung tidak sama dengan kemampuan mengapung. Dalam prinsip mekanika ada beberapa faktor yang berkaitan dengan tinggi rendahnya gaya apung sebagai berikut: 1. Bentuk tubuh, 2. Ukuran tulang, 3. Perkembangan otot, 4. Jaringan lemak, 5.
Berat benda, 6. Kapasitas paru-paru. menunjukan bahwa perempuan memiliki gaya apung lebih besar dari laki-laki, dengan jumlah 15 orang perempuan 13 orang mengapung atau sama dengan $86,7 \%$. Sedangkan laki-laki dari 62 orang terdapat 26 orang yang mengapung atau sama dengan $41,9 \%$.

Menurut McGinnis (2010:244) di dalam tubuh kita terdapat otot dan tulang yang mempunyai kepadatan lebih dari $1000 \mathrm{~kg} / \mathrm{m}^{3}$ (gravitasi spesifik lebih dari 1.0). tulang yang tersusun adalah $16 \%$ dari berat total orang dewasa. dan lemak mempunyai kepadatan kurang dari $1000 \mathrm{~kg} / \mathrm{m}^{3}$ (gravitasi spesifik kurang dari 1.0). kapasitas paru-paru pada laki-laki sekitar $=3.000-6.100 \mathrm{ml}$ BTPS, sedangkan perempuan sekitar $=2.500$ $4.500 \mathrm{ml}$ BTPS (Sumber: pusat kesegaran jasmani dan rekreasi, Depdikbud, 1996). (http:///PerbedaanKomposisiTubuhWanitavs PriaSaatMengejar.com.html) pada wanita persentase lemak tubuh mencapai hampir $25 \%$, sedangkan pria total lemak tubuh hanya berkisar 15\%. Kepadatan otot Pria cenderung memiliki massa otot jauh lebih banyak dari pria karena memiliki hormon testoterone. Perbandingan hormon testoterone pria dan wanita adalah 10:1.

Kerangka pada wanita dan juga kepadatan tulangnya kira- kira 25\% lebih rendah dari pada pria dan rasio tuas sendiendinya secarafungsional juga kurang efektif. Ada faktor lain yang mempengaruhi gaya apung yaitu kandungan air dalam tubuh manusia karena Kandungan air pada tubuh manusia jumlahnya jauh lebih besar bila dibanding dengan kandungan zat - zat yang lain. Kandungan air pada tubuh bayi bisa 
mencapai $75 \%$ - $80 \%$ yang kemudian seiring dengan pertumbuhan tubuhnya, kandungan air pada manusia dewasa berkurang hingga mencapai $60 \%$ - 65\% untuk pria dan $50 \%$ $60 \%$ untuk wanita. Kandungan air pada Otak manusia terdiri dari $85 \%$. Sedangkan tulang kita terdiri dari $10 \%-15 \%$ air (https:/kandungan_air_tubuh_inf.html).

\section{PENUTUP}

\section{Simpulan}

Berdasarkan hasil pengamatan (observasi) terhadap gaya apung. Data yang diperoleh menunjukkan bahwa setiap mahasiswa memiliki gaya apung yang berbeda. Data yang diperoleh melalui penjumlahan dari hasil pengamatan (observasi) terhadap gaya apung mahasiswa penjaskesrek semester 2 Universitas Bengkulu yang berjumlah 77 orang dengan menggunakan rating scale dan check list maka di peroleh hasil, bahwa mahasiswa dengan keadaan atau posisi Mengapung sebanyak 39 orang atau 50,64\% , mahasiswa dengan keadaan atau posisi Melayang sebanyak 19 orang atau 24,67\%, dan mahasiswa dengan keadaan atau posisi tenggelam sebanyak 19 orang atau 24,67\%. Hasil penelitian tes Antropometri yang terdiri dari IMT (Indek Massa Tubuh) dan presentase lemak sebagai tes pendukung dari hasil pengamatan yang dilakukan terhadap gaya apung. Hasil tes Antropometri merupakan tes untuk melihat tipe tubuh dan komposisi dalam tubuh. Bisa kita lihat dari hasil perolehan data IMT (Indek Massa Tubuh) dan presentase lemak tersebut meskipun bentuk tubuh sama tetapi komposisi tubuh yang berbeda. Perolehan data tersebut maka dihubungkan dengan hasil pengamatan terhadap gaya apung ternyata mahasiswa memiliki gaya apung yang berbeda pada saat berada di dalam air.

Saran

Berdasarkan pada kesimpulan di atas maka dapat dikemukakan saran sebagai berikut:

1. Mahasiswa harus memahami konsep gaya apung yang ada dan menerapkan konsep tersebut pada saat melakukan gerakan dalam berenang tanpa mengalami kesulitan dan dalam melakukan teknik mengapung.

2. Mahasiswa perlu melakukan adaptasi terhadap media olahraga yang berbeda dari cabang olahraga yang mereka kuasai terlebih dahulu karena olahraga renang merupakan olahraga yang di lakukan didalam air.

3. Pemahaman tentang ilmu biomekanika olahraga yang harus ditambah untuk menunjang pengetahuan terhadap biomekanikan dalam olahraga dan dapat diterapkan dalam dalam melakukan berbagai macam gerakan dalam olahraga.

4. Para mahasiswa juga harus memiliki kemauan yang keras untuk bisa menguasai olahraga renang.

5. Bagi para pelatih renang agar dapat mempelajari prinsip-prinsip biomekanika olahraga agar dapat menghasilkan atlet yang berkualitas bukan saja dari segi fisik tetapi juga dari segi tehnik.

\section{DAFTAR PUSTAKA}

Arikunto, Suharsini. (2010). Prosedur penelitian suatu pendekatan praktik. Jakarta: Rineka cipta.

Endang. (2001). Penelitian Pendidikan. Bengkulu: FKIP UNIB

Hendromartono, Soejoko. (1992). Olahraga pilihan Renang. Departemen pendidikan dan kebudayaan derektorat 
jenderal pendidikan tinggi proyek pembinaan tenaga kependidikan.

Haller, David. (2008). Belajar Berenang. Bandung: Pionir Jaya

Imam Hidayat. (1997). Biomekanika. Bandung: UPI Bandung.

McGinnis. (2010). Biomechanics of sport and exercise. Diterjemahkan oleh Wijayanto, Adi dan Lestari, Sri. Jakarta: program magister (S2) pasca sarjana UNJ.

Karnadi, Indik dkk. (2007). Renang. Edisi 1. Jakarta: Universitas Terbuka.

Kirkendall R Don., et al. 1980. Measurement and evaluation for physical educators. Jakarta: program S3 PPS IKIP Jakarta

Kurnia, dadeng. (2003). Teknik dasar dan lanjutan. Jakarta selatan: pelatihan nasional pelatih akuatik.

Misbahuddin dan Hasan, Iqbal. (20013). Analisis data penelitian dengan statistik. Edisi ke-2. Jakarta: Bumi Aksara. 